(2) The surface water must be of approximately the same salinity as that of the sea bottom; if it has a much lower salinity, its density may not be increased by a reduction of temperature to an extent sufficient to set up convection movements reaching to the sea-bottom. (3) It must be cooled to a slightly lower temperature than that of the water at the sea-bottom, for its adiabatic contraction, by pressure, as it sinks, must warm it slightly; this may be the cause of the slight increase in the temperature of oceanic water as we approach great depths-an increase which has been attributed to the emission of heat by radio-active substances in the oceanic bot'smdeposits. (4) The formation of ice on the seasurface may favour convection currents by raising the salinity of the superficial water; but this is not an important factor.

The cold bottom water of the North Atlantic Ocean originates in a restricted area of sea, outside the boundaries of the southerly-flowing polar current, and lying to the south-east of Greenland. Some of this water may also proceed from the surface of the Norwegian Sea after flowing over the Faröe-Iceland ridge.

Incidentally Dr. Nansen directs attention to the presence of Mediterranean water in the channel between Ireland and Rockall. This originates from warm and dense water flowing out as an intermediate current through the Straits of Gibraltar. The presence of this water in British seas was pointed out by Dickson in Igog as the result of observations made in 1903 by Wolfenden. Dr. Nansen in 1909 referred to the methods of these observations as "so inaccurate as to be of little use." Nevertheless, he now adopts the conclusions drawn from them, without, however, referring to Dickson's prior discovery.

\section{J. J.}

\section{SOUTH AFRICAN INSTITUTE FOR MEDICAL RESEARCH.}

SOUTH AFRICA has decided to have an institute for medical research on the same lines as the Pasteur Institute in Paris, the Lister Institute of Preventive Medicine in London, or the Rockefeller Institute in New York. To this end a new building is now in pror _ss of erection in Johannesburg, and is expectr $A$ to be complete in about twelve months.

A site has been provided by the Government, and we understand that the cost of building and equipping the new institute will be provided by the Witwatersrand Native Labour Association. The maintenance of the institution will be undertaken by the Government of South Africa and the association in equal shares.

A very satisfactory feature of the institute will be its close proximity to the largest hospital in South Africa, with which it is intended that it should work in conjunction. It will also be equipped with four wards for the purpose of treating patients, who will be the subject of special study.

$$
\text { No. } 227 \mathrm{O}, \text { VOL. 9I] }
$$

From the present plans, the institute seems to be suitably arranged, and will be an imposing structure. It will comprise, in a main block, forming a two-storied quadrangle, the institute offices, experimental and observation hospital, animal house, mortuary, and director's house. Ample space is allowed here for future extension. Of this main block the northern and southern sides are prolonged eastwards and westwards to form two further quadrangles. These will contain the hospital wards and research laboratories, also library, museum, and further laboratories. The building will carry as well a lecture theatre, basement workshops and storage rooms, and a number of rooms for miscellaneous scientific purposes. A dome eighty feet in height will crown the building, and will carry a finial emblematic of the surrender by Death of his secret, and we understand that a second dome of equal magnitude is aspired to. Although we realise that an institute which is intended to render valuable service to the State should be housed in fashion suitable to the importance of the work it is to undertake, we sincerely hope that contemplation of the domes and the finial will not distract the attention of the authorities from the fact that the success of their scheme will essentially depend upon the personnel of the staff and the funds made available for scientific investigation.

The research work of the institute is, we understand, to be primarily directed towards the industrial diseases of the Transvaal, but all diseases will come under its scope. It is intended that research fellowships shall be available for medical men, in order that they may carry out special lines of investigation; also it is hoped that in the near future medical students will be enabled to undertake courses in pathology and bacteriology at the institute, of a character which can now only be attended in Europe.

Two appointments to the staff of the institute have already been made : the director of the institute will be Dr. Watkins Pitchford, and the statistician Dr. G. D. Maynard, both of whom have already accomplished sound work in connection with one or other of the public health organisations of the colonies now forming the Dominion of South Africa.

\section{EDUCATION OF THE AUDITORY CENTRES. ${ }^{1}$}

PROF. MARAGE, who is well known as an otologist and for his researches in physiological acoustics, has issued a small but suggestive pamphlet on what he terms the education of the auditory centres. It is known that there are cases in the clinique of the aurist where there is sensitiveness to even feeble noises while there is deafness to music and to speech. In others the patient may hear noises, music, and even speech sounds, but without any understanding of the meaning of the speech sounds. Prof. Marage

1 "Education et Rééducation des Centres auditifs." By Prof. Marage. Pp. 15. (Paris, I9 Rue Cambon.) 
explains these facts on the supposition that the cause is not to be sought in the mechanism of the ear alone, but in the relation of this mechanism to different parts of the brain.

The paths by which nervous impulses, generated by a sonorous vibration, say, in the cochlea, are communicated to the brain, are very complicated, and come into anatomical connection with many nervous centres. Such centres may be considered as being of higher and lower orders, and the nervous impulses may pass from lower to higher, calling forth at each stage a particular sensation-say, that of a noise or of musical sensations-until they reach the highest cerebral centres where there is the appreciation of all kinds of auditory sensations, such as noises, music, and speech.

Prof. Marage's method of stimulating the ear by his ingenious syren is well known. This instrument can transmit to the drumhead sonorous waves of a measured intensity (that is, the airpressure is measured), and the special quality of each vowel tone is produced by sending the waves of pressure through resonators moulded on the form of the mouth and throat cavities for each vowel. Thus, by using the syren methodically, the ear may be stimulated by tones that, as regards both intensity and quality, are natural to it, instead of tones produced by tuning-forks, or noises, or by spoken words. Thus the ear and the nerve centres may be put through a course of education, a kind of drill, in short, produced by the syren. The results are said to be very encouraging with cases of whole or partial deafmutism.

Prof. Marage also gives in this pamphlet copies of tracings of vowel-forms produced by this syren which are well worthy of study, but he does not mention how these beautiful photographs were obtained. The gist of the whole matter is that in attempting to explain auditory mechanisms, we must not confine our attention to the ear alone, but to the ear as associated with auditory nerve centres. The investigation, in short, becomes more and more complicated.

JOHN G. MCKENDRICK.

\section{NATURAL HISTORY IN CEYLON.}

SPOLIA ZEYLANICA is an excellent quarterly publication designed to promote a knowledge of the natural history of Ceylon and its surrounding seas. It was established by Prof. A. Willey (now at Montreal) some eight or nine years ago when he was director of the Colombo Museum, and has been kept up since with admirable skill and energy by his successor, Dr. Joseph Pearson the present editor. The part for January, I9I3, contains, along with several notes on land and fresh-water animals, three articles of special interest on pearl-oyster fisheries.

The first article, by Captain Legge, "Master Attendant" at Colombo and inspector of the pearl banks, is semi-popular, and is written rather from the navigator's and the historian's point of view, containing notes and stories of fisheries and celebrated pearls. Here and there in Captain Legge's chatty account of his personal adventures on the pearl banks one comes on quite important observations, such as, when describing a walk in diving-dress over the sea-bottom :

Immediately I walked off the "paar" I was upon very loose sand, in waves like giant furrows in a ploughed field; whilst for quite two feet high above the ground there was sand in suspension. Here oysters are covered up, buried and destroyed immediately.

Yet some recent writers have argued that there can be no movement of the sand on the bottom, and that beds of oysters cannot be silted up by moving sand.

Captain Legge gives us an additional instance of the now well-known danger to beds of oysters from predatory elasmobranch fish, as follows :

At the inspection in November, 1902, I decided that a certain bed was quite the gem of those to be fished in March, 1903; the oysters were larger and older than any others I had inspected, and were very plentiful; however, as I was passing over this spot on my way back at the end of the inspection, I observed a very large shoal of rays in the vicinity. In the following March, about the second week of the fishery, I moved to this my pet bed of oysters, only, however, to be told by the divers that there were no living oysters there. I at once descended in the diving dress and found the bottom of the sea strewn with empty oyster shells, each valve turned nacre upwards and shining, giving a very curious effect, whilst each shell or valve was broken obviously by external pressure into three pieces. This could only have been done by the powerful jaws and teeth of the ray.

The second article is a well-considered, judicial account of the scientific work on the Ceylon pearl banks in the last decade, 1902 to 1912 , by the editor, Dr. Pearson, director of the Colombo Museum and Government Marine Biologist. Dr. Pearson passes in review the scientific exploration of the pearl banks in I902, the recommendations in Prof. Herdman's report to the Government, the formation of a financial syndicate in 1906 to take over a twenty years' lease of the fisheries at a large annual rental, their two highly profitable fisheries which cleared the ground of adult oysters, and then the subsequent failure of yield and resulting barren condition of the banks. The various operations suggested and performed are discussed, and the conclusion is reached that:

The work subsequent to Herdman's reports gives very little evidence that his recommendations have been carried out seriously.

Dr. Pearson brings together a good deal of argument in favour of the possibility of oysterbeds being buried and lost by movements of the sand, and he quotes some personal observations, made on the bottom by the inspector of pearl banks, such as :

What impressed me most was that the spots I dived on last March, which were then level rock, with a coating of 3 or 4 in. of sand, had now as much as a foot of sand in places. All over the sand was in fairly deep ridges, not so deep as the ridges of the

No. 2270 , VOL. 9I] 